\title{
Acinetobacter Iwoffii
}

National Cancer Institute

\section{Source}

National Cancer Institute. Acinetobacter Iwoffii. NCI Thesaurus. Code C86095.

A species of aerobic, Gram negative, rod and cocci shaped bacteria assigned to the phylum Proteobacteria. This bacteria is nonmotile, oxidase negative, catalase positive and does not produce acid from galactose, mannose, rhamnose or lactose. This bacteria is found in the normal flora of humans and can cause infections, such as mening itis, septicemia, and pneumonia. 